\title{
Labirintos do trabalho no cinema brasileiro: Fragmentos para uma história da representação da classe trabalhadora no filme de ficção
}

///////////// Alfredo Suppia ${ }^{1}$

1. Doutor em Multimeios (Unicamp), professor de cinema da Universidade Federal de Juiz de Fora (UFJF), pós-doutorando na ECAUSP. E-mail: alsuppia@gmail.com. 
Resumo Este artigo procura isolar o tema "trabalho" do contexto mais amplo de "popular", no sentido de observar mais detidamente formas e estratégias de representação da classe trabalhadora no cinema brasileiro, sugerindo um itinerário de investigações para pesquisas futuras mais "verticalizadas". Assim, propomos uma trajetória de análise que parte do período silencioso, passando pela emergência do cinema moderno no Brasil e pelos anos 1980, chegando ao cenário da "Retomada" (período aproximado entre 1993 e 2003).

Palavras-chave Cinema, trabalho, classe trabalhadora, Cinema Novo, Cinema da Retomada.

Abstract This article aims to investigate representations of the work and the working class in Brazilian cinema, outlining an itinerary for further research with a focus on film and labor. Thus, departing from a brief examination of the silent era, this analysis encompasses the emergence of modern cinema in Brazil (Cinema Novo) and the 1980s film production, culminating with the latest revival of Brazilian cinema in the late 20th century (Cinema da Retomada).

Keywords Cinema, labor, working class, Cinema Novo, Cinema da Retomada. 


\section{Introdução}

No panorama do cinema brasileiro de ficção em longa-metragem, um corpus coeso de filmes consistentemente voltados ao tema do trabalho e ao personagem do(a) trabalhador(a) no país ainda resta por ser mais claramente definido e examinado. No quadro do cinema documentário brasileiro, a situação é diversa. Um corpus de filmes explicitamente dedicados ao tema do trabalho - seja de forma conservadora, solidária ou progressista - é mais visível, bem como reflexões mais detidas sobre esse objeto. Exemplos de investigações contemporâneas mais focadas no tema do trabalho e da representação da classe trabalhadora no cinema brasileiro (notadamente o documentário) podem ser buscados em Bernardet (1978 e 2003), Cardenuto (2009) e Jorge (2010).

No campo específico da ficção, as contradições da classe trabalhadora no contexto do processo precário e tardio de modernização brasileira já aparecem em filmes do período silencioso como Eletrificação da Companhia Paulista de Estradas de Ferro (1923), A Sociedade Anonyma Fabrica Votorantim (1922), ou São Paulo, a Symphonia da Metrópole (1929), de Adalberto Kemeny e Rodolfo Lustig. Fabrica Votorantim, por exemplo, ilustra as ambiguidades da modernização em São Paulo, sugerindo curiosas contradições entre discurso e imagem, conforme demonstrado por Ismail Xavier em sua análise do contraste entre a disciplina industrial e a espontaneidade dos trabalhadores no filme (2006, p. 58-59). De acordo com Amir Labaki, em São Paulo, a Symphonia da Metrópole 
O foco central é o trabalho - ou antes, os trabalhadores. Ei-los saindo de casa, desafiando a neblina matinal, esforçando-se em fábricas e lojas, em canteiros de obras e redações de jornal, improvisando um almoço ligeiro pelas ruas da cidade, enfrentando o crescente tráfego. Uma visita à principal penitenciária da cidade flagra a aposta disciplinadora da reeducação dos detentos pelo trabalho. (LABAKI, 2006, p. 33)

\section{Cinema Novo}

Nos anos 1950 e 1960 o cinema brasileiro representou a classe trabalhadora de forma predominantemente conservadora - o operário industrial via de regra retratado como sujeito passivo, pacato e coadunado com os interesses do capital "empreendedor". Exemplo desse tipo de representação pode ser buscado na filmografia de Jean Manzon, realizador de uma série de documentários encomendados por empresários e capitalistas. Segundo Cardenuto,

\footnotetext{
Nesses seus filmes, realizados principalmente da década de 1960 em diante, a publicidade em torno de um produto vinha acompanhada de uma projeção ideológica na qual a iniciativa privada tornava-se articuladora de um pacto social em benefício da classe popular. (2009, p. 71)
}

Com a emergência do Cinema Novo, no entanto, novas estratégias de problematização do trabalho e de representação da classe trabalhadora brasileira, mais progressistas e politicamente engajadas, projetaram-se no horizonte cinematográfico nacional. $\mathrm{Na}$ verdade, um olhar diverso sobre a realidade das condições de trabalho no Brasil já podia ser identificado em antecedentes do movimento como Aruanda (1960), de Linduarte Noronha, sobre uma comunidade quilombola no interior da Paraíba, ou os filmes de Nelson Pereira dos Santos, Rio 40 Graus (1955) e Rio Zona Norte (1957).

O ímpeto político do Cinema Novo, com impacto direto sobre uma ética (um "cinema da verdade") e uma estética (um cinema "violento", no sentido de ideologicamente agressivo e dissidente de estilos conservadores - notadamente o classicismo hollywoodiano), acabou lançando (ainda que enviesadamente) as bases para uma transformação da figura do trabalhador no cinema brasileiro: de um 
personagem reconfortado e pacífico a um personagem politicamente engajado e disposto à luta.

Esse Mundo é Meu (1964), de Sérgio Ricardo, é bom exemplo de obra mais visivelmente debruçada sobre a realidade do trabalhador brasileiro - na esteira do "olhar neo-realista" antecipatório de Nélson Pereira dos Santos. O filme abre auspiciosamente com o plano de uma pipa em movimento, metáfora que antecipa os altos e baixos, meneios e devaneios das estórias paralelas, protagonizadas por dois trabalhadores brasileiros: Pedro (Sérgio Pitanga), metalúrgico branco, e Toninho (Antônio Pitanga), engraxate negro. O movimento da pipa antecipa a instabilidade na trajetória dos dois personagens principais e seus respectivos pares românticos: Luzia, companheira de Pedro, e Zuleika, a mocinha dos sonhos de Toninho. Pedro e Toninho moram na mesma favela, são vizinhos. Quando Pedro e Luzia estão bem, celebrando seu amor, Toninho sofre pela distância de Zuleika, moça fogosa que namora um "malandro de calça branca". A bicicleta, sonho primário de Toninho, parece a chave para a conquista definitiva de seu amor.

A miséria e a opressão afeta brancos e negros, porém de forma sutilmente diversa. Pedro tem alguma consciência de classe, da realidade de sua condição de oprimido, sentimento que não é plenamente partilhado por Luzia. Toninho é pragmático e próativo - em momentos de felicidade é ele quem cantarola e assobia a canção-título de Sérgio Ricardo, "Esse Mundo é Meu”. Seus objetivos são claros: uma bicicleta e a moça admirada. Pedro é hesitante, faltalhe ímpeto e coragem, enquanto Toninho finalmente age em função de seus objetivos primordiais. Quando Luzia engravida, Pedro não consegue o aumento com o patrão. Em paralelo, Toninho vai se apropriar da bicicleta de um padre, numa cena-chave do filme. $\mathrm{O}$ diálogo entre Toninho e o Padre alegoriza, com ironia e humor, uma reação inaudita no nível mais programático e coletivo das ações populares. Devendo o aluguel do barraco e em piores condições financeiras, Luzia decide abortar, a contragosto de Pedro - que porém não age para impedíla. O desfecho é trágico, com a morte de Luzia e da criança, lançando Pedro numa espiral de solidão e desamparo. Enquanto isso, Toninho conquista sua felicidade sobre duas rodas, finalmente na companhia da cobiçada Zuleika. O filme termina numa chave dúplice, ambígua: de um lado, Pedro na pior; de outro, Toninho em pleno gozo de seus desejos. Viúvo, de volta ao 
trabalho na metalúrgica, Pedro tenta convocar os companheiros para a greve, numa atitude tardia que parece não encontrar apoio.

A última fala de Pedro, "estarei sozinho?", ganha eco se pensarmos no contexto social e político do Brasil naquele momento. Esse Mundo é Meu antecedeu a ditadura militar em pouquíssimo tempo. O filme foi lançado no infame lo de abril de 1964, dia do golpe, e nesse sentido é também sinistramente premonitório do inferno que se abateu sobre o país.

Esse Mundo é Meu é um filme que fala de trabalho - mas o patrão fica ausente, é apenas intuído ou representado iconicamente, como nas cenas inspiradas no Teatro do Oprimido. Além disso, o discurso ideológico operado pelo filme, de viés marxista, se oferece menos em diálogos do que por meio das metáforas construídas a partir do trabalho de câmera e do som. A montagem vertical, contraponto entre a banda sonora e a banda imagética que recorre a diálogos em off, fornece desde o início uma linha estrutural a todo o filme. O filme de Sérgio Ricardo, com foco no trabalhador braçal, morador da favela, antecipa em um ano outro filme também debruçado sobre o tema do trabalho: São Paulo S/A (1965), de Luís Sérgio Person. No filme de Person, no entanto,o foco recai sobre o trabalhador de classe média e a ascensão de uma pequena burguesia industrial corrupta.

Associado ao que Fernão Ramos (1987, p. 358) definiu como "segunda trindade" do Cinema Novo - os filmes Terra em Transe (1967), de Gláuber Rocha, O Desafio (1965), de Paulo César Saraceni e O Bravo Guerreiro (1968), de Gustavo Dahl -, São Paulo S. A. tem como protagonista um bem-sucedido empresário do ramo de autopeças, Carlos (Walmor Chagas). Percebendo a futilidade do meio em que vive, assim como as forças opressoras, alienantes e reificantes do universo do trabalho na cidade grande industrializada, o personagem mergulha em crise existencial. Tenta abandonar tudo, inclusive a família, mas acaba retornando a São Paulo.

São Paulo S/A se enuncia de forma parcialmente não-linear, e pontuado por alguns procedimentos anti-naturalistas, como quando se Carlos dirige para a câmera. O pano-de-fundo da trama é a explosão ou milagre da indústria automobilística brasileira. Carlos prospera inicialmente às custas de corrupção: como inspetor de qualidade das peças fornecidas à Volkswagen, ele atua para que a empresa compre as engrenagens e eixos fabricados por seu amigo 
Arturo, imigrante italiano. Mas o esquema é descoberto e Carlos acaba demitido. Desempregado, Carlos aceita oferta de Arturo para trabalhar em sua pequena fábrica, a Autopeças Carracci.

No trabalho com Arturo, Carlos é um funcionário com poderes de sócio. Ele é responsável pelo sucesso nas vendas da empresa e guarda segredo sobre as falcatruas do patrão, como sonegação fiscal e irregularidades trabalhistas. Carlos usa sua posição privilegiada de gerente e o conhecimento que tem sobre os ilícitos da empresa para chantagear Arturo. Com isso, leva uma vida financeiramente confortável, vindo a se unir a Luciana (Eva Wilma), típica jovem de classe-média que busca um "bom casamento".

A sequência do jantar na casa de campo de Arturo, com a família dele e de Carlos reunidas (mulheres e filhos), ilustra com propriedade o criticismo à burguesia individualista, apoiada em privilégios e iniquidades. Em diálogos assíncronos, Carlos e Luciana expõem seus valores pessoais. Carlos: "Arturo é o grande exemplo. Tudo que você deseja na vida é que eu seja como ele, não é mesmo? Arturo é bom. Arturo é rico. Massacra seus operários. Rouba o quanto pode. Tem grandes e desonestas ambições. Mas Arturo é um exemplo. Veja como trata seus filhos. Só quer o bem para eles. Fazer sua família feliz, é tudo que Arturo deseja." Luciana: "E assim será para você, Carlos. E eu serei feliz. E todos em torno a nós dois serão felizes. Será assim, amém.”

Ao ficar sabendo que Luciana pretende investir dinheiro de seu pai na fábrica de autopeças de Arturo, com o intuito de tornar o marido sócio de fato do italiano, Carlos se revolta e só pensa em "dar o fora". Ele avisa Luciana que vai abandonar a família. Deixa sua casa, rouba um carro e pega a estrada aos gritos de "Tchau São Paulo!”, “Tchau, Luciana!”. A certa altura da viagem, Carlos pára o carro para dormir. Ao acordar, ele muda de idéia. Abandona o veículo à beira da estrada e pega carona com um caminhoneiro, de volta a São Paulo. Prestes a retornar à metrópole, retoma em pensamento as palavras de angústia que já o haviam afligido sobre o Viaduto do Chá: "Recomeçar, recomeçar, recomeçar. Mil vezes recomeçar. Recomeçar de novo, recomeçar sempre. Recomeçar..."

Fernão Ramos aponta a ausência da dimensão popular no filme de Person, em favor de forte presença da representação da classe média (1987, p. 362). De toda maneira, o tema do trabalho 
e a problematização das tensões que afetam o trabalhador continuam genuinamente presentes em São Paulo S/A, numa das mais evidentes manifestações do gênero no cinema brasileiro. A cena em que Carlos perambula desorientado pelo centro de São Paulo, intercalada a imagens de máquinas em atividade sob voz off do mesmo personagem, é claramente evocativa de filmes de vanguarda e do montagismo soviético dos anos 1920, porém em tom distópico e expressivamente remissivo aos conceitos marxistas de alienação e reificação. Emprestando algo do referencial imagético de Metropolis (1927), de Fritz Lang, a cena em questão explicita a tomada de consciência de Carlos acerca de sua condição descartável, repetitiva, alienada, sua existência também como "peça" de uma grande engrenagem industrial a serviço da acumulação de capital, e o consequente açodamento de seus valores humanistas.

\section{Anos 1980}

1981 é um ano-chave no que diz respeito à problematização da classe trabalhadora pelo cinema brasileiro, com a estréia de dois longas-metragens de ficção que merecem destaque: $O$ Homem que Virou Suco, de João Batista de Andrade, e Eles Não Usam BlackTie, de Leon Hirszman - obras de dois cineastas particularmente debruçados sobre o tema do trabalho e do trabalhador no Brasil.

O Homem que Virou Suco narra as desventuras de um humilde migrante nordestino, Deraldo (José Dumont), que se muda para São Paulo na esperança de viver de sua poesia. Na cidade grande, o protagonista acaba confundido com um operário que esfaqueara o patrão, e a partir daí se vê forçado a cumprir tarefas braçais em sua luta pela sobrevivência, especialmente no contexto da construção civil. O filme reconstrói, dessa forma, a trajetória de inúmeros migrantes nordestinos anônimos, aos quais se atribui a construção da maior metrópole da América do Sul. Dotado de espírito contestador, o personagem principal entra em choque com o status quo e, nesse trajeto, o filme revela as tensões subjacentes à realidade do trabalho no Brasil. Pela via do poeta que se vê forçado a trabalhar pesado, entre diversos outros aspectos, o filme reinscreve em pauta questões de ordem marxista, como a velha antinomia "trabalho intelectual vs. trabalho manual” (ver BERNARDET, 2003, p. 272-273), bem como a busca por cidadania. 
Eles Não Usam Black-Tie, por sua vez, narra um conflito familiar polarizado em torno de dois personagens da cena operária paulista, um pai e seu filho (Gianfrancesco Guarnieri e Carlos Alberto Ricelli, respectivamente), trabalhadores na mesma indústria, porém com orientações ideológicas distintas e representativos de um choque geracional que assume contornos edipianos. $\mathrm{O}$ conflito aparentemente familiar é, na verdade, vetorizado por forças externas à família, contando com elementos catalisadores que provêm do ambiente de trabalho e do panorama de tensão devido à greve que se instala. De acordo com Cardenuto (2012), os personagens do pai e do filho encarnam uma situação em que todo o processo político dos anos anteriores ao filme - as paralisações de 1978, a greve de 1979 no ABC paulista, a greve de 1980, a formação do PT (Partido dos Trabalhadores) e o surgimento da Central Única dos Trabalhadores (CUT), em 1979, vinha moldando uma identidade nova para um operário que, historicamente, sempre fora visto como figura passiva e submissa - uma nova identidade de luta.

Eles Não Usam Black-Tie é uma adaptação para o cinema da peça homônima de Gianfrancesco Guarnieri, escrita originalmente em 1956, e que estreou em São Paulo em 22 de fevereiro de 1958, marcando o início da fase nacionalista do Teatro de Arena. Segundo Giovanni Alves, a peça "trata do proletariado industrial da grande indústria fordista-taylorista num país de formação capitalista colonialprussiana de industrialização hipertardia" (2010, p. 326). A exemplo do que teria acontecido com Greve! (1979) e O Homem que Virou Suco, de Joaquim Batista de Andrade, o filme de Hirszman também guarda reminiscências da experiência do diretor com a filmagem de ABC da Greve (1979) (JORGE, 2010, p. 137-8).

Em Eles Não Usam Black-Tie, os personagens representam vetores ideológicos bem marcados. O pai, Otávio, identifica-se com os ideais da coletividade, personagem pivotal e repositório de utopias que se diluiram após 1968. Seu filho, Tião, encarna uma juventude individualista e pragmática. Santini (Francisco Milani) ilustra o militante esquerdista inflamado, pró-ativo ao extremo, no limiar da impulsividade e violência motivada por uma bandeira ideológica a princípio justa e meritória. Bráulio (Milton Gonçalves) faz o papel do trabalhador negro, duplamente discriminado, porém de atitudes moderadas e conciliatórias, uma voz de ponderação em meio a ações cínicas, ingênuas ou impulsivas. Jesuíno (Anselmo Vasconcelos) 
representa o lúmpen ou proletário-marginal, o individualista sem escrúpulos que não hesita em obter as maiores vantagens em detrimento dos colegas de profissão.

Uma cena de conversa entre Tião e Jesuíno retoma um ethos já enunciado em São Paulo S/A, e que será depois retomado, em cores acentuadas, por O Invasor (2001) de Beto Brant. No refeitório, à hora do almoço, Jesuíno revela que dedurou aos patrões colegas envolvidos na organização da greve, e sugere que Tião faça o mesmo. Jesuíno aconselha: "Vai inventando uns nomes porque eles vão te cobrar também...". Tião se revolta com a atitude do colega. Jesuíno se justifica: "Calma garoto. A vida não é assim como a gente quer não. É a nossa chance, companheiro. É preciso levar vantagem em tudo. Um jeitinho aqui, outro ali, pronto! Você está com um escritório, secretária, e ninguém vai te perguntar como você conseguiu. Você pode matar, roubar, que ninguém vai te perguntar. E tu (sic) ainda diz: aproveitei a chance, companheiro. E uns e outros aí chegaram até a presidente." O cinismo de Jesuíno antecipa a imoralidade de dois personagens em O Invasor (2000), o empresário Giba e o matador Anísio - ambos revelam em diálogos crenças muito similares à do lumpemproletário de Eles Não Usam Black Tie.

Alves sugere que Otávio e Bráulio talvez sejam representações ficcionais de personagens reais, as lideranças comunistas durante a greve dos metalúrgicos do ABC paulista em 1978, 79 e 80 "que adotaram tom moderado no confronto com o capital", enquanto Santini encarna lideranças do "sindicalismo autêntico" que fundou o PT e a CUT em 1979 (2010, p. 363-4). Sobre o desfecho do filme, Alves observa que, "Na história imediata do Brasil, o assassinato de Bráulio reproduz, no plano ficcional, o assassinato do operário Manuel Fiel Filho, morto pelos órgãos de repressão da ditadura militar em 1976" (2010, p. 371).

A despeito de quaisquer estereótipos, simplificações ou esquematizações, Eles Não Usam Black-Tie é um dos raros filmes brasileiros que elevam o(a) trabalhador(a) à condição de protagonista e, por meio de sua encenação de conflitos intraclasse, ilustra o processo (marxiano) de passagem de "classe em si" para o de "classe para si" - isto é, “(...) o processo de passagem de uma classe que tem uma existência apenas numérica, dada pela concretude de seus membros, para uma classe que toma consciência de seu 
papel político como agente transformador da sociedade capitalista” (JORGE, 2010, p. 148).

Filmes como Esse Mundo é Meu, São Paulo S/A e Eles Não Usam Black-Tie revelam certos padrões no cinema brasileiro em termos de representação de trabalhadores, tais como a persistência do ambiente fabril como palco das demandas, o foco na subjetividade e nos conflitos individuais ou familiares contra ou justapostos ao quadrante do trabalho (mesmo nos filmes mais "devotados" às causas trabalhistas) e a constante "movimentação" dos protagonistas. Os personagens principais, em geral trabalhadores, estão empre engajados numa dupla jornada, geográfica e subjetiva, ou em manobras de esquiva face às pressões do mundo do trabalho. Não à toa Zeca (Gianfrancesco Guarnieri) ama sua bicicleta em $\mathrm{O}$ Grande Momento (1958), o mesmo objeto de desejo de Toninho em Esse Mudo é Meu. E em São Paulo S/A, Carlos trabalha no setor automotivo, sendo o veículo automotor um ícone e "chave de leitura" no contexto do filme de Person. Vistos em conjunto, embora pareçam complementares, há pouca conexão ou organicidade entre as obras acima. Uma conexão mais profunda, porém, resultante de um exame retrospectivo, emerge do cotejo entre São Paulo S/A e O Invasor.

\section{Cinema da Retomada}

No contexto mais amplo e heterogêneo do cinema brasileiro mais recente, destacamos um filme em especial: O Invasor (2001), de Beto Brant, filme acentuadamente crítico da corrupção transclassista e da violência social brasileira.

$\mathrm{O}(\mathrm{s})$ conflito(s) em O Invasor emergem, de fato, a partir da problemática do trabalho e do estilhaçamento da cidadania, resultantes da exploração e exclusão que ocasionam o surgimento de "áreas intersticiais", "limbos sociais" nos quais vicejam personagens elusivos.

O Invasor narra eventos que sucedem a uma sinistra negociata entre dois bem-sucedidos empresários de classe média do ramo da construção civil, Giba (Alexandre Borges) e Ivan (Marco Ricca). Ambos contratam um matador de aluguel, Anísio (Paulo Miklos), para eliminar o terceiro e mais poderoso sócio de sua empresa contrutora, Estevão Araújo (George Freire). Giba quer eliminar Estevão porque este se recusa a incluir a empresa, Araújo Associados, num contrato 
com o governo. O filme de Brant abre com o exato momento de contratação do pistoleiro, num botequim na zona sul de São Paulo, em regime de câmera subjetiva. O ponto de vista é misterioso neste momento, mas depois saberemos que se trata do olhar de Anísio, procedimento que sugere a consequente "captura" moral, financeira e até mesmo física dos demais personagens da trama por parte do pistoleiro de aluguel. Giba e Ivan dirigem-se em tom vacilante para a Anísio, que dialoga em off.

Quando Giba e Ivan se despedem na madrugada seguinte à contratação de Anísio, o primeiro relembra ao segundo: "Não pense que você não está sujando as mãos, só porque não é você que está fazendo o serviço. Dá no mesmo. Bem-vindo ao lado podre da vida." A trilha sonora de O Invasor, mescla de rap, punk e heavy metal, assume função de comentário equivalente às cenas teatralizadas em Esse Mundo é Meu, com alguns "ensaios" de montagem disjuntiva, como no velório de Estevão e sua mulher.

Para Alves, o filme dramatiza “(...) um processo de inversão social que caracteriza a era do sociometabolismo da barbárie: a lumpenização da "classe média' e o aburguesamento do lumpesinato" (2010, p. 285). O autor acrescenta que "A linha narrativa do filme O Invasor expõe um processo de invasão/ocupação/envolvimento de Anísio no mundo burguês. Da empresa à família, o lúmpen Anísio constrói seus laços sociais capazes de efetivá-lo no consórcio de interesses pequeno-burguês" (ALVES, 2010, p. 305).

Ainda no terço inicial do filme, com Estevão assassinado, Giba e Ivan estão livres para firmar o desejado contrato milionário com o governo. Não tarda, porém, para que a culpa e o arrependimento comecem a atormentar o vacilante Ivan, à medida em que este submerge na realidade dos negócios escusos de Giba (o sócio também é um dos donos de uma casa de prostituição de luxo), bem como em sua filosofia, excessivamente pragmática. Mas o maior conflito, o choque que inclusive sugere o título do filme, reside na reaparição do assassino de aluguel.

Vítimas de constrangimento e chantagem, Giba e Ivan se vêm obrigados a ceder espaço à presença de Anísio. A crise de consciência de Ivan se acentua enquanto, em contrapartida, Giba vai se tornando cada vez mais belicoso. Ao mesmo tempo, abre-se espaço para a escalada do "invasor" Anísio, que acaba conquistando a simpatia e 
afeto de Marina (Mariana Ximenes), filha de Estevão, o empresário assassinado. No terço final do filme ocorre uma inversão de papéis. Anísio ocupa a casa de Estevão, veste robe de seda, desfruta dos favores da namorada rica, Marina, filha do casal que executou.

No rastro da trajetória do "invasor", toda uma série de sintomas e tensões relativas à problemática do trabalho e de classe no Brasil acabam tangenciadas. Alves observa oportunamente que “(...) $O$ Invasor mostra o vínculo intrínseco entre a corrupção que assola a máquina estatal e a corrosão ético-moral das relações humanas fetichizadas no trato dos negócios privados entre amigos" (2010, p. 297). Num contexto de concentração de renda, garantia de privilégios, abuso de poder e exclusão, Anísio é o agente intermediário executor dos trabalhos práticos demandados pelo sistema. Trata-se de um peronagem mercurial, um Hermes delituoso que se multiplica para a manutenção do sistema de exploração e exclusão. Sendo fundamental seu relativo anonimato e virtual ausência da esfera de cidadania, tais "agentes" devem se contentar com o poder da força num circuito restrito de manobras, força esta autorizada por um suposto "mecenas" e "titereiro". Por isso Alves assinala que "[o] lúmpen Anísio é um personagem heurístico que expõe com notável expressividade a miséria social do capital como poder impositivo. Ele catalisa as prerrogativas gerenciais (e morais) do capital" (2010, p. 302), sendo “(...) o alter ego perverso de Giba e Ivan. É o espectro do lúmpen que invade seu território para lembrá-los, como reminiscência grotesca, o que eles são, de fato - capitalistas, detentores do poder do capital, donos do mundo, proprietários que não dão trela para ninguém" (ALVES, 2010, p. 307). A fala de Anísio em O Invasor relembra a fala de Jesuíno a Tião em Eles Não Usam Black-Tie. Um pragmatismo perverso contamina o discurso do excluílo e legitima a opressão: dono pode tudo, matar, roubar, mandar prender.

O final de O Invasor - a situação-limite cristalizada na deambulação de Ivan por uma avenida na periferia da cidade, após bater seu carro - acentua o caráter labiríntico da trama, que culmina no epílogo absolutamente verista, anti-climático e desilusório. Não há resolução ética possível, não há saída no horizonte civilizado. O filme não se resolve porque espelha uma realidade irresoluta. A angústia de Ivan é sufocada pelo cinismo. Encurralado, subentendese que Ivan será a próxima vítima - na verdade, ele já o é, trata-se do único personagem algemado na cena final. 


\section{Cotejos}

Guardadas as devidas proporções entre ambos, e a despeito das diferenças estilísticas e de contexto social, político e econômico que cercam os dois filmes, São Paulo S/A e O Invasor têm alguns pontos em comum que merecem ser investigados. Por exemplo, os dois filmes centram foco sobre a classe média economicamente ativa - o proletário altamente qualificado que ocupa postos de gerência ou o pequeno-burguês proprietário de meios de produção (ainda que não integrante dos oligopólios detentores do comando geral do mercado). Os personagens principais nos dois filmes são engenheiros - em São Paulo S/A, um engenheiro do setor de auto-peças; em O Invasor, da construção civil. Ambos os personagens mergulham numa crise ética e existencial profunda. Em ambos os filmes, o protagonista masculino de classe média, homem próspero de carreira promissora e família perfeita, sucumbe às contradições de seu papel, à hipocrisia e coerções impostas pela vida burguesa "feliz".

No caso do filme de Person, a crise ética e existencial tem motivação aparentemente muito menos violenta que no caso do filme de Brant. Embora não apresente o mesmo nível de complexidade e "carregamento das tintas" que em O Invasor, a corrupção e as tensões de relacionamento entre a classe média, a pequena-burguesia e o proletariado propriamente dito - ou lumpenproletariado -, também se enunciam em São Paulo S/A. Ambos os filmes partilham uma visada distópica sobre a realidade do trabalho no Brasil - com uma exacerbação do "labirinto" que culmina em verdadeiro cul-de-sac no filme de Beto Brant. Em outras palavras, o Ivan de O Invasor poderia ser o personagem-herdeiro do Carlos de São Paulo S/A, num contexto em que a modernidade utópica entrevista no filme de Person teria fracassado definitivamente.

Comparações entre São Paulo S/A e O Invasor já foram feitas anteriormente. Ismail Xavier, por exemplo, investigou as simetrias e contrastes entre o que ele denomina a "cidade-máquina" (São Paulo S/A) e a "cidade-arquipélago" (O Invasor) (2006, p. 18-25). Sob essa perspectiva, os personagens de ambos os filmes poderiam ser tomados como duplos (Carlos-Ivan; Arturo-Giba), com uma diferença: em O Invasor, o crime hediondo parece passar ao centro do mundo dos negócios, torna-se a chave para a administração dos grandes empreendimentos. Giba e Ivan são assassinos, e os personagens de $\mathrm{O}$ 
Invasor evocam um paradigma de desumanização muito mais agudo do que no filme de Person (XAVIER, 2006, p. 21). Em resumo, O Invasor dramatiza uma equação na qual o encastelamento da pequena burguesia brasileira, "lumpenizada" (ALVES, 2010) e conivente com a corrupção histórica no país, gera fatores imponderáveis.

Não bastassem as similitudes ou equivalências já citadas, São Paulo S/A e O Invasor guardam ainda mais um aspecto comum digno de nota: diferente de uma série de documentários e filmes de ficção - Rio 40 Graus, Barravento, Greve!, ABC da Greve, Eles Não Usam Black-Tie, etc. -, a relação entre o cineasta e seu objeto de interesse não é exatamente desnivelada nos filmes de Person e Brant, diretores identificados com a classe média brasileira, os quais, em seus filmes, tematizam tensões do trabalho no seio dessa própria classe média. Ou seja, São Paulo S/A e O Invasor são filmes nos quais, ao menos momentaneamente, o "diretor implícito" - tomemos aqui de empréstimo a categoria de "autor implícito" da crítica literária - pertence ao universo que retrata, a classe média ou, talvez mais precisamente, a pequena burguesia brasileira. Por mais engajados e solidários que filmes como Aruanda, Rio 40 Graus e Eles Não Usam Black-Tie possam ser, são todos filmes que tematizam classes a rigor extemporâneas ao "diretor implícito". Não pretendemos destrinchar a complexidade desse aspecto neste trabalho, mas vale a pena remetermos a Ella Shohat e Robert Stam, quando estes problematizam o fato de que "grupos historicamente marginalizados não têm controle sobre sua própria representação” (2006, p. 270).

Vale lembrar que O Invasor estreou em 2001, nos últimos momentos do auge de um relativamente longo período de estagnação econômica do Brasil, identificado com os dois mandatos do governo de Fernando Henrique Cardoso - rescessão justificada pela (sic) busca da estabilização econômica, equilíbrio fiscal, recuperação da confiabilidade no mercado internacional e controle da inflação. Em 2003, Luís Inácio Lula da Silva ganhou as eleições e o Brasil começou a dar sinais de retomada do crescimento. Atualmente, porém, todo o esforço dos anos de "penúria" do governo FHC parece desmanchar-se ante a volta da inflação e a manutenção da corrupção, visível em escândalos sucessivos envolvendo as mais altas cúpulas de governo, seja nas esferas municipal, estadual ou federal - corrupção esta, diga-se com justeza, que se traduz como a única instituição 
nacional que de fato atravessa governos, um após o outro, sem sofrer maiores abalos ou declínios.

O cotejo de São Paulo S/A com O Invasor parece sugerir que a problemática do trabalho no país, organicamente atrelada a aspectos mais amplos como a história econômica e a ética nacional, permanece um "nó-górdio" ou zona de indeterminação. Nesse sentido, o cinema parece sempre "um paso atrás" das transformações operadas na arena do trabalho. Um filme como O Invasor demonstra, entre outros aspectos, que esse "ciclo" de investigações sobre o trabalho e o trabalhador brasileiro - manobra iniciada talvez com Linduarte Noronha e Nelson Pereira dos Santos - ainda não se fechou. Ao contrário, nota-se contínua agudização do conflito e rebaixamento de perspectivas. A produção mais recente - filmes como Os 12 Trabalhos (2006), de Ricardo Elias, Linha de Passe (2008), de Walter Salles, Trabalhar Cansa (2011), de Marco Dutra e Juliana Rojas, ou ainda Cores (2012), de Francisco Garcia - demonstra alguns desvios (mas também continuidades), mas não poderá ser melhor examinada aqui, cabendo a uma etapa posterior desta pesquisa.

\section{Notas finais}

Cardenuto (2012) observa oportunamente que as crises do trabalho têm aparecido em fragmentos de filmes brasileiros, porém não ocupam o centro da dramaturgia. É o que podemos observar em filmes como O Grande Momento (1958), de Roberto Santos, ou A Hora da Estrela (1986), de Suzana Amaral, nos quais o plano mais intimista ganha destaque, embora a prblemática do trabalho permaneça como pano de fundo. Tal diagnóstico vai ao encontro de uma de nossas hipóteses centrais neste breve estudo, a de que o cinema de ficção nacional nunca foi arena de debates mais sistemáticos e pronunciados acerca da realidade do trabalho e da classe trabalhadora no país. Aos olhos do observador mais atento, é obviamente possível a configuração de um corpus de filmes. Tais obras, porém, não se conectam entre si de forma mais orgânica e duradoura. A tarefa de configuração de um corpus mais coeso de filmes dedicados ao tema do trabalho e à figura do(a) trabalhador(a) permanece incompleta, bem como análises mais pormenorizadas da representação do trabalho no cinema brasileiro de ficção. 
Outro aspecto constatado por esta breve análise diz respeito à longevidade de postulados ou preceitos marxistas mais tradicionais no cinema brasileiro, sobretudo a partir dos anos 1960. O operário ainda é a figura central em representações da classe trabalhadora, e a fábrica continua sendo palco privilegiado de conflitos (Cf. ALVES, 2010, p. 325).

De Aruanda e Rio 40 Graus, passando por O Invasor e filmes ainda mais contemporâneos, a produção cinematográfica ficcional brasileira parece ecoar de forma um tanto quanto generalizada postulados marxistas e gramscianos (como a concepção de classes subalternas). Mesmo a fábula de O Invasor, que se distancia momentaneamente do palco fabril, instala-se parcialmente no cenário da construção civil, de certa maneira locus análogo à fábrica e reminiscente de outras ficções predecessoras, como O Homem que Virou Suco. Marina Soler Jorge observa oportunamente que “[p] esquisadores da Sociologia do Trabalho debatem-se sobre o fim do emprego industrial, o fim da classe trabalhadora tradicional, o fim da sociedade industrial, e outras mudanças drásticas que parecem ter ocorrido no mundo do trabalho" (2010, p. 132). A autora esclarece que, enquanto alguns estudiosos decretam o fim do trabalho como aspecto fundamental de análise da sociedade contemporânea caso de André Gorz (1987) -, outros procuram demonstrar que, “(...) embora alterações fundamentais tenham ocorrido, o trabalho continua sendo uma categoria sociológica imprescindível para se pensar a atualidade" (JORGE, 2010, p. 133) - caso de Ricardo Antunes (2008). Jorge acrescenta que "[a]queles que encampam esta última posição têm se desdobrado para empreender uma contextualização da teoria de classes marxista numa conjuntura que à primeira vista parece obviamente desfavorável à existência das classes tradicionais" (2010, p. 133).

Ainda à guisa de conclusão, os três filmes mais detidamente enfocados neste breve estudo - Esse Mundo é Meu, São Paulo S/A, Eles Não Usam Black-Tie e O Invasor - parecem resumir uma curiosa continuidade ideológica no cinema brasileiro voltado ao tema do trabalho. Embora São Paulo S/A e O Invasor estejam mais próximos entre si, ética e esteticamente falando, do que de Esse Mundo é Meu ou Eles Não Usam Black-Tie - o filme de Brant parece uma versão consumadamente distópica do épico de Person -, todos os quatro problematizam a corrupção enraizada e difusa, a prática 
de subterfúgios e ilícitos em todas as classes sociais e os vícios nas relações entre as esferas pública e privada no país. De certa maneira, os quatro filmes atestam a influência dos postulados marxistas sobre abordagens audiovisuais do trabalho, a relevância contínua do palco fabril e as estratégias lícitas ou ilícitas de sobrevivência num sistema viciado. E embora $O$ Invasor venha a ser o mais cruel e depressivo do grupo de filmes comentados, cumpre notar que a melancolia e a desesperança são constantes também em Esse Mundo é Meu, São Paulo S/A e Eles Não Usam Black-Tie. 


\section{Referências}

ALVES, Giovanni. Trabalho e Cinema: O mundo do trabalho através do cinema, vol. 3. Londrina: Práxis; Bauru: Canal 6, 2010 .

BERNARDET, Jean-Claude. Cineastas e Imagens do Povo. São Paulo: Companhia das Letras, 2003.

CARDENUTO, Reinaldo. “O golpe no cinema: Jean Manzon à sombra do Ipes". ArtCultura, Uberlândia, v. 11, n. 18, p. 59-77, jan.-jun. 2009. Disponível em http://www.seer.ufu.br/ index.php/artcultura/article/view/7305/4712. Acessado em 06/11/2012.

CARDENUTO, Reinaldo. Entrevista. ABCD em Revista: $O$ cinema nacional e o trabalho. TVT. Exibido em 13/07/2012. Parte 1 disponível em http://www.youtube.com/ watch?v=GwabxyzKeIU. Parte 2 disponível em http://www. youtube.com/watch? $\mathrm{v}=\mathrm{dBm} 0 \mathrm{CyxiEQI}$. Parte 3 disponível em http://www.youtube.com/watch?v=IEE2pk6YtiM. Acessado em 02/11/2012.

GORZ, Andre. Adeus ao proletariado. São Paulo: Forense Universitária, 1987.

JORGE, Marina Soler. "Imagens do movimento operário no cinema documental brasileiro”. ArtCultura, Uberlândia, v. 12, n. 21, p. 131-148, jul.-dez. 2010. Disponível em http:// www.artcultura.inhis.ufu.br/PDF21/m_jorge.pdf. Acessado em 06/11/2012.

RAMOS, Fernão (org.). História do Cinema Brasileiro. São Paulo: Edart, 1987.

SHOHAT, Ella e STAM, Robert. Crítica da Imagem Eurocêntrica. São Paulo: Cosac \& Naify, 2006.

XAVIER, Ismail. "São Paulo no cinema: expansão da cidade- 
máquina, corrosão da cidade-arquipélago. Sinopse 11, 2006, pp. 18-25.

Artigo recebido em outubro de 2013 e aprovado em junho de 2014. 